\title{
Evaluation of dietary supplement advertisements in popular Spanish, Chinese, and Korean media outlets: a cross sectional study
}

Anthony Lee, Lesley Joanna Vásquez, Wing Chi Wong and Jaekyu Shin ${ }^{*}$

\begin{abstract}
Background: The prevalence of dietary supplement (DS) advertisements in non-English daily periodicals, weekly periodicals, and television in the United States is unknown. Additionally, it is unclear if the claims presented in these advertisements are validated. This study aims to compare the prevalence of DS advertisements and percent of validated claims in DS advertisements among popular English and non-English daily periodicals, weekly periodicals, and television.
\end{abstract}

Methods: This is a cross-sectional study involving daily periodical, weekly periodical, and television advertisements for DS in English, Spanish, Chinese, and Korean in San Francisco Bay Area and Los Angeles Area, California, USA. Study outcomes are percent prevalence of DS advertisements, percent of claims in DS advertisements that made therapeutic claims, and percent of validated claims in DS advertisements. Claims in DS advertisements were validated by using the effectiveness rating of the Natural Medicines Comprehensive Database and/or identifying a supporting randomized controlled trial (RCT).

Results: The prevalence of DS advertisements across all three media outlets were $0 \%$ in English, $0 \%$ in Spanish, $14.8 \%$ in Chinese, and $11.4 \%$ in Korean. Across all three media outlets, DS advertisements were significantly more prevalent in both Asian languages than in English $(p<0.001)$. None of the products identified in English media outlets made a therapeutic claim whereas $18.6 \%$ of products identified in non-English media outlets did. None of the claims in DS advertisements had an effective rating. Only one product identified in English media outlets had supporting data from an RCT.

Conclusions: Our data suggest that DS advertisements are more common in Asian language media outlets than in English and Spanish language media outlets. Given the lack of validated claims in DS advertisements, rigorous evaluations of their claims should be carried out to guide and protect consumers.

Keywords: Dietary supplements, Advertisements, Claims, Prevalence, Validation

* Correspondence: Jaekyu.shin@ucsf.edu

Department of Clinical Pharmacy, School of Pharmacy, University of

California, 521 Parnassus Avenue, C-152, San Francisco, CA 94143-0622, USA 


\section{Background}

Dietary supplements are widely used in the United States. According to data from the National Health Interview Survey, $17.9 \%$ of adults used a non-vitamin, non-mineral dietary supplement in 2012 [1]. The use of dietary supplements may be higher in non-English speaking populations than in the English-speaking population. For example, 50-90 \% of the Hispanic population may use dietary supplements [2].

According to the Dietary Supplement Health and Education Act of 1994 (DSHEA), a dietary supplement is defined as "a product intended for ingestion that contains a dietary ingredient intended to add further nutritional value to [supplement] the diet". A dietary ingredient may be one or any combination of a vitamin, mineral, herb or other botanical, amino acid, concentrate, metabolic constituent, extract or any dietary substance for use by people to supplement the diet by increasing their total dietary intake [3]. Under DSHEA, dietary supplement manufacturers can make 3 types of claims: health (e.g., vitamin D may help reduce the risk of osteoporosis), nutrient content (e.g., high vitamin D content), and structure/function (e.g., vitamin D helps maintain strong bones). However, they are not allowed to make therapeutic claims such as treatment, prevention, or cure of a specific disease (e.g., vitamin D treats osteoporosis).

Direct consumer advertisements of dietary supplements in media outlets such as daily periodicals, weekly periodicals, and television are an important marketing tool since dietary supplements do not require a prescription to obtain and advertisements can reach a large number of target populations. In the US, advertisements of dietary supplements are regulated by the Federal Trade Commission (FTC). According to the FTC, advertisements of any dietary supplement products must be truthful, not misleading, and substantiated [4]. In addition, dietary supplement advertisements are required to have a two-part DSHEA disclaimer: "These statements have not been evaluated by the Food and Drug Administration" and "This product is not intended to diagnose, treat, cure, or prevent any disease".

Dietary supplement advertisements in non-English media outlets may not follow these regulations. In a study evaluating compliance of dietary supplement advertisements in Korean newspapers in the Los Angeles area, $84.5 \%$ of the advertisements made a disease claim and only $18.4 \%$ had the DSHEA disclaimer [5]. In addition, only $13.6 \%$ of products had experimental data available to support advertised claims. Given the availability of dietary supplements without medical supervision, the high rate of misleading dietary supplement advertisements in non-English media outlet can pose a health risk to minority populations.
Asians and Hispanics currently make up roughly $21 \%$ of the US population. Importantly, these two ethnic groups saw the biggest increase in population from 2000 to 2010 in the US [6]. Despite the high use of dietary supplements in non-English speaking populations, it is unknown how common dietary supplement advertisements are in popular non-English media outlets and whether claims made in these advertisements follow US regulations compared with those in popular English media outlets. Therefore, the objective of this study is to compare prevalence of dietary supplement advertisements and proportion of claims in dietary supplement advertisements following US regulations in popular Spanish, Chinese, Korean, and English media outlets in the San Francisco and Los Angeles areas which have a large number of Hispanic, Chinese, and Korean populations.

\section{Methods}

This cross-sectional study involved dietary supplement advertisements in two daily periodicals, two weekly periodicals, and one TV network in each respective language. Since this study did not involve human subjects, it did not require approval by Committee for Human Research Protection at the University of California San Francisco.

\section{Media outlets \\ 1) Daily Periodicals}

We selected one English, two Chinese, and two Korean daily periodicals in the San Francisco area. We also selected one English and two Spanish daily periodicals in the Los Angeles area because Spanish daily periodicals were unavailable in the San Francisco area. The selected daily periodicals were the San Francisco Chronicle and the Los Angeles Times for English; La Opinión and Hoy Los Ángeles for Spanish; World Journal and Sing Tao Daily for Chinese; and The Korea Times and The Korea Daily for Korean.

Since advertisements were mostly local and the non-English daily periodicals were collected in the San Francisco and Los Angeles areas, we selected the San Francisco Chronicle and the Los Angeles Times as the English counterparts. These two were the most popular local English daily periodicals in their respective areas and had over 600,000 circulations per day [7-10]. The selected non-English daily periodicals were popular in the US for each respective language, although Korean daily periodicals did not have circulation data $[11,12]$. Spanish and Chinese daily periodicals had over 100,000 circulations per day [13-16]. 


\section{2) Weekly periodicals}

We selected two local weekly periodicals that were free and readily available in markets and grocery stores in the San Francisco area, the major distributors of nonEnglish weekly periodicals. The selected weekly periodicals were SF Weekly and San Francisco Bay Guardian for English; El Avisador and El Tecolote for Spanish; East Week and Sing Tao Times for Chinese; and Joogan Hyundae and Kyocharo News for Korean. Circulation data were available only for the English weekly periodicals and El Tecolote. The English weekly periodicals had over 60,000 circulation per week and El Tecolote over 10,000 [17-19].

\section{3) $T V$}

We selected one popular and nationally available TV network in each respective language. The selected TV networks were Columbia Broadcasting System (CBS) for English; KDTV Univision for Spanish; Jade Channel for Chinese; and Korean Broadcasting System (KBS World) for Korean. The TV networks were selected based on ratings in the US or countries speaking the respective languages [20-23].

\section{Advertisements}

We considered advertisements of any products, services, or ideas that had an identifiable sponsor.

\section{1) Daily and weekly periodicals}

We included advertisements of any size, separated from articles, editorials, columns, and bulletins. We excluded classified advertisements in daily periodicals because some daily periodicals had no health/medicine/dietary supplement advertisements in their classified advertisements section.

\section{2) $T V$}

We included TV advertisements that lasted for at least 5 seconds and were separate from regular TV programs. We excluded TV advertisements presented during regular TV programs (e.g. thanking sponsors during the program) because they were often about manufacturers.

\section{Advertisements of a dietary supplement}

We used the DSHEA definition of a dietary supplement and considered only advertisements of a product taken by mouth that contains a dietary ingredient as a dietary supplement advertisement [3, 24].

\section{Data collection}

We collected product names, claims, ingredients, and manufacturer names, use of testimonials, and presence of the DSHEA disclaimer [24]. We also obtained the location of the manufacturer by visiting its website. We categorized each dietary supplement ingredient as herbal, vitamin, mineral, amino acid, or other. We counted the number of advertisements according to advertising units of each periodical. We counted advertisements that appeared more than once throughout the study to determine the prevalence of a dietary supplement advertisement.

\section{Schedule of data collection}

We collected data for a total of 15 weeks, from September 30th, 2013 to January 12th, 2014. For daily periodicals and TV, we collected data in a rotating schedule which involved one weekday and one weekend each week. We observed TV advertisements from $7 \mathrm{pm}$ to $10 \mathrm{pm}$ local time on study days based on show ratings during this time [23]. We sequentially selected weekdays (e.g., Monday for weeks 1, 6, and 11, Tuesday for week 2, 7 , and 12 etc.). For daily periodicals, we selected only Saturdays as a weekend day because of the unavailability of a Sunday issue for some daily periodicals. For TV, we alternated Saturdays and Sundays (Saturday for odd weeks and Sunday for even weeks). This rotating schedule was designed to 1) capture as many different advertisements as possible because on certain non-English TV channels, the number and content of TV advertisements differed between weekdays and weekends; and 2) to identify trends among advertisements between weekdays and weekends.

\section{Purposes of dietary supplement products and definition of a therapeutic claim}

We grouped the purpose of dietary supplement products as general health, disease-specific, sexual aid, cosmetics, and weight loss based on the claim made in the advertisement. We collapsed sexual aid, cosmetics, and weight loss into one group as there were not common. We considered the purpose of a dietary supplement product as cosmetics if the advertisement contains a claim to improve structure or function for a better appearance (e.g., removing wrinkles). If a claim contained a name of a disease and the word diagnose, prevent, cure, treat, or mitigate, then it was classified as therapeutic.

\section{Validation of claims}

We validated claims made in dietary supplement advertisements against effectiveness ratings by the Natural Medicines Comprehensive Database since this database rating is used by https://www.nlm.nih.gov/medlineplus/. $[25,26]$ When evaluating claims, we did not distinguish between therapeutic claims versus other types of claims; instead, we treated all claims equally. The Natural Medicines Comprehensive Database has 6 levels of rating to assess effectiveness: effective, likely effective, possibly effective, possibly ineffective, likely ineffective, and ineffective (Table 1) [27]. For a dietary supplement product 
with one ingredient, we searched for either the product or an individual ingredient for a rating. For a dietary supplement product with two or more ingredients, we searched the product for a rating. For a product with multiple claims, we considered only the highest rating. For example, if one claim was rated as "effective" and the other claim rated as "likely ineffective", then we considered it as "effective". If an ingredient or product was not found on www.naturaldatabase.com, we searched Medline for a randomized controlled trial (RCT) published up to February 28, 2014. We included RCTs comparing dietary supplement products to either placebo or standard treatment in human subjects for the effect related to the claim. The effect related to the claim was either a clinical outcome (e.g., incidence of cancer) or a surrogate outcome (e.g., decrease in blood pressure), depending on the claim. For our search, we used the name of the product or ingredient as keywords and did not limit languages. We also visited the website of the manufacturer of the product to obtain any citations of RCTs on the product. If a dietary supplement product had more than one ingredient, the product itself had to be the subject of a claim in a randomized clinical trial. We considered the claim as validated if it had an effective rating or a RCT report that 1 ) it had a statistically significant lower incidence of adverse clinical outcomes or better improvement in surrogate outcomes compared with placebo or standard treatment or 2) it had no statistically significant difference in the incidence of adverse clinical outcomes or improvement in surrogate outcomes compared with standard treatment.

\section{Statistical analysis}

We considered each data collection day as a unit of observation. There were a total of 30 data collection days for daily periodicals and TV, and a total of 15 data collection days for weekly periodicals. We calculated percent of advertisements that were dietary supplement advertisements per data collection day. After removing duplicate dietary supplement advertisements, we calculated percent of dietary supplement advertisements which had a validated claim. If the advertisements were identical in the same or different outlets in the same language, then they were considered duplicates. There were no identical dietary supplement products advertised in different languages.

We tested normality of the data with the KolmogorovSmirov test. We used the Kruskal-Wallis test to compare the median percentage of dietary supplement advertisements by language and media outlet. We conducted a pair-wise comparison by using the Wilcoxon rank sum test. We used Fisher's exact test to compared percent of dietary supplement advertisements with a validated claim among the languages. We considered a p-value $<0.05$ as statistically significant and used SAS (version 9.2, Cary, NC, USA).

\section{Results}

Out of a total of 40,292 advertisements, 1,614 (4.0\%) were about dietary supplements. Overall, dietary supplement advertisements were more prevalent in Chinese and Korean media outlets than those in English counterparts (Table 2). In particular, $10-14 \%$ of all advertisements in Chinese and Korean media outlets were about a dietary supplement product whereas less than $1 \%$ in English counterparts were $(P<0.001$ by pairwise comparison). Dietary supplement advertisements were not common in Spanish media outlets.

Dietary supplement advertisements were generally more common on TV than daily or weekly periodicals $(p<0.0001)$; more than $20 \%$ of all Chinese and Korean TV advertisements were about a dietary supplement product. All three media outlets for Chinese and Korean had a statistically significant higher prevalence of dietary supplement advertisements than its English counterparts.

Table 1 Levels of Evidence for Assessing Effectiveness

\begin{tabular}{ll}
\hline Effectiveness Rating & Level of Evidence \\
\hline Effective & $\begin{array}{l}\text { The product has passed a rigorous scientific review equivalent to a review by the FDA, Health Canada, or other governmental authority } \\
\text { and has been found to be effective for a specific indication as an OTC drug, orphan drug, or prescription drug product. }\end{array}$ \\
Likely Effective & $\begin{array}{l}\text { Reputable references generally agree that the product is effective for the given indication, based o9n two or more randomized, } \\
\text { controlled, clinical trials involving several hundred to several thousand patients, giving positive results for clinically relevant endpoints } \\
\text { and published in established, refereed journals. }\end{array}$ \\
Possibly Effective & $\begin{array}{l}\text { Reputable references suggest that the product might work for the given indication based on one or more clinical trials giving positive } \\
\text { results for clinically relevant endpoints. }\end{array}$ \\
Possibly Ineffective & $\begin{array}{l}\text { Reputable references suggest that the product might not work for the given indication based on one human study giving negative } \\
\text { results for clinically relevant end-points. } \\
\text { Likely Ineffective }\end{array}$ \\
Reputable references generally agree that the product is not effective for the given indication, based on two or more randomized, \\
controlled, clinical trials giving negative results for clinically relevant end-points and published in established, refereed journals. \\
Ineffective
\end{tabular}


Table 2 Median number of total advertisements and percentage of dietary supplement advertisements per day in English, Spanish, Chinese, and Korean media outlets

\begin{tabular}{|c|c|c|c|c|c|c|c|c|c|c|c|c|}
\hline \multirow[t]{2}{*}{ Language } & \multicolumn{3}{|l|}{ All Media } & \multicolumn{3}{|c|}{ Daily Periodicals } & \multicolumn{3}{|c|}{ Weekly Periodicals } & \multicolumn{3}{|l|}{ Television } \\
\hline & Total ads & $\%$ DS Ads & P value* & Total ads & $\%$ DS Ads & $P$ value* & Total ads & $\%$ DS Ads & P value* & Total ads & $\%$ DS Ads & $P$ value* \\
\hline English & $109(24-371)$ & $0(0-3.6)$ & $\mathrm{N} / \mathrm{A}$ & $80(24-268)$ & $0(0-0)$ & $\mathrm{N} / \mathrm{A}$ & $251(189-371)$ & $0(0-0)$ & $\mathrm{N} / \mathrm{A}$ & $109(94-123)$ & $0(0-3.6)$ & $\mathrm{N} / \mathrm{A}$ \\
\hline Spanish & $15(9-140)$ & $0(0-25)$ & 0.25 & $29(9-45)$ & $0(0-2.7)$ & 0.06 & $119(11-140)$ & $0.7(0-0.9)$ & 0.001 & $11(9-20)$ & $0(0-25.0)$ & 0.08 \\
\hline Chinese & $122.5(13-313)$ & $14.8(0-32.9)$ & $<0.001$ & $247(157-313)$ & $0.5(0-1.3)$ & $<0.001$ & $43(13-75)$ & $18.8(13.9-28.6)$ & $<0.001$ & $99(61-128)$ & $24.3(14.7-32.9)$ & $<0.001$ \\
\hline Korean & $44(32-80)$ & $11.4(0-34.4)$ & $<0.001$ & $44(39-45)$ & $10.3(6.7-18.2)$ & $<0.001$ & $37(35-47)$ & $2.17(0-14.3)$ & $<0.001$ & $55(32-80)$ & $26.1(16.4-34.4)$ & $<0.001$ \\
\hline
\end{tabular}

Data are expressed as median (range)

The total ads are a median of total advertisements during each observation period. The $\%$ DS ads are a median of $\%$ DS ads on each observation

Abbreviations: DS, dietary supplement; ads, advertisements; N/A, not applicable

Comparison of percentage of dietary supplement advertisements among the languages within each media type: all $p<0.0001$ by Kruskal-Wallis test

*Pair-wise comparison with English advertisements by Wilcoxon rank sum test 
Table $\mathbf{3}$ Characteristics of dietary supplement products identified in the advertisements

\begin{tabular}{lllll}
\hline Language & $\begin{array}{l}\text { Total number of unique } \\
\text { DS products }\end{array}$ & Single ingredient (\%) & $\begin{array}{l}\text { Containing a herbal } \\
\text { ingredient (\%) }\end{array}$ & $\begin{array}{l}\text { Manufacturer located in } \\
\text { the US (\%) }\end{array}$ \\
\hline English & 7 & $2(28.6)$ & $1(14.2)$ & $7(100.0)$ \\
Spanish & 7 & $0(0)$ & $2(66.7)$ & $4(66.7)$ \\
Chinese & 76 & $15(19.7)$ & $58(82.9)$ & $21(36.2)$ \\
Korean & 57 & $20(35.7)$ & $42(84.0)$ & $19(33.3)$ \\
\hline
\end{tabular}

Abbreviations: DS dietary supplement, US United States

angredients were unidentifiable in 4, 7, and 2 dietary supplement products advertised in Spanish, Chinese, and Korean media outlets, respectively

${ }^{b}$ The location of the manufacturer of 1 and 18 dietary supplement products advertised in Spanish and Chinese media outlets was unidentifiable

Out of a total of 156 unique dietary supplement advertisements, only 6 (3.8\%) contained the DSHEA disclaimer: 5 out of 7 English and 1 out of 8 Spanish dietary supplement advertisements had it. Testimonials were used in 17 dietary supplements advertisements: 16 in $80(20 \%)$ Chinese and 1 in $62(1.6 \%)$ Korean dietary supplement advertisements used a testimonial.

Out of a total of 147 unique dietary supplement products identified in the dietary supplement advertisements, $134(91.1 \%)$ had an identifiable ingredient (Table 3). The majority of the products $(84.6 \%)$ contained two or more ingredients. The percentage of dietary supplement products containing a single ingredient was not significantly different among the 4 languages $(p=0.10)$. Of the types of dietary supplement ingredients, herbal ingredients were most common: $70.1 \%$ of dietary supplement products contained an herbal ingredient. In particular, dietary supplement products identified in advertisements in Chinese and Korean media outlets had a significantly higher percentage of an herbal ingredient than those in the English counterparts $(p=0.0005)$. None of the dietary supplement products identified in advertisement in English media outlets were manufactured outside of the US whereas 77 (63.6 \%) of those identified in advertisements in non-English media outlets were imported.

Out of 136 dietary supplement products with a claim in their advertisements, 59 (40\%) were for general health, 57 (38.8 \%) for disease-specific, and 20 (14.7 \%) for sexual aid, cosmetics, or weight loss purposes (Table 4). Therapeutic claims were made in 24 products (17.6\%; Table 4). None of the products identified in
English media outlets made a therapeutic claim whereas $18.6 \%$ of products identified in non-English media outlets did. Claims in the advertisements of only 4 products had a possibly effective or likely effective rating: 1 with a likely effective rating and 1 with a possibly effective rating were identified in English, 1 with a likely effective rating in Chinese, and 1 with a possibly effective rating in Korean media outlets. However, none of the claims had an effective rating. Of the 109 products without a rating at www.naturaldatabase.com, only one product identified in English media outlets had data from a RCT that supported its claims. As a result, $96.3 \%$ (131 out of 136 products) had a claim that was not substantiated.

\section{Discussion}

In this study, there were three important findings: 1) compared with popular English media outlets, Chinese and Korean media outlets had a statistically significantly higher prevalence of dietary supplement advertisements, with over $20 \%$ of TV advertisements being dietary supplement advertisements; 2) a substantial number of dietary supplement advertisements in non-English media outlets did not follow the regulation. Whereas none of the dietary supplement advertisements in English media outlets made a therapeutic claim, $18.6 \%$ of those in non-English media outlets did. In addition, whereas 5 out of 7 in English media outlets contained the DSHEA disclaimer, only 1 out of 149 dietary supplement advertisements in non-English media outlets did; and 3) advertisements of only one product identified in English media outlets had a claim supported by the highest level of evidence (i.e., effective rating or data from an RCT).

Table 4 Types and validation status of health claims made in dietary supplement advertisements

\begin{tabular}{llllllll}
\hline Language & $\begin{array}{l}\text { Total number of unique } \\
\text { DS products }\end{array}$ & $\begin{array}{l}\text { General } \\
\text { health }\end{array}$ & Disease-specific & $\begin{array}{l}\text { Sexual aid/Cosmetics/ } \\
\text { Weight loss }\end{array}$ & $\begin{array}{l}\text { Therapeutic } \\
\text { claims (\%) }\end{array}$ & $\begin{array}{l}\text { Any claims with an } \\
\text { effective rating* (\%) }\end{array}$ & $\begin{array}{l}\text { Any claims supported } \\
\text { by data from RCT (\%) }\end{array}$ \\
\hline English & 7 & 4 & 3 & $0 / 0 / 0$ & $0(0)$ & $0(0)$ & $1(14.2)$ \\
Spanish & 7 & 0 & 4 & $3 / 0 / 0$ & $2(28.6)$ & $0(0)$ & $0(0)$ \\
Chinese & 76 & 31 & 25 & $3 / 6 / 2$ & $13(19.4)$ & $0(0)$ & $0(0)$ \\
Korean & 57 & 24 & 25 & $3 / 2 / 1$ & $9(16.4)$ & $0(0)$ & $0(0)$ \\
\hline
\end{tabular}

Abbreviations: DS dietary supplement, $R C T$ randomized controlled trial

*based on rating by www.naturaldatabase.com

No health claims were made 9 and 2 dietary supplement advertisements in Chinese and Korean media outlets 
To our knowledge, this is the first study that compared the prevalence and content of dietary supplement advertisements in 3 popular media outlets in 4 different languages in the US.

Chinese and Korean media outlets had a significantly higher prevalence of dietary supplement advertisements than English and Spanish counterparts. Many factors may have contributed to a higher prevalence of dietary supplement advertisements in Chinese and Korean media outlets. Advertisements may be a main source of information on dietary supplements that Koreans use to make a decision on purchasing a dietary supplement product [28].

However, these advertisements do not follow US regulations. Even though we used a strict definition of a therapeutic claim, we found that over $18 \%$ of claims made in dietary supplement advertisements in nonEnglish media outlets met our definition and none of the dietary supplements had a high level of evidence to support their claims. None of the therapeutic claims were included in the pre-approved health claims list. Moreover, some claims could mislead consumers and potentially delay their receiving effective treatments. For example, one DS product advertisement claimed a better efficacy in reducing blood glucose than approved drugs and stated that it did not require a coverage approval by an insurance plan. Because manufacturers of about two thirds of dietary supplement products were located outside of the US, they may not be fully aware of US regulations. Since many consumers use dietary supplements to treat a disease and people who do not speak English are unlikely to have access to the health care system in the US, a higher prevalence of dietary supplement advertisements combined with claims without validation in nonEnglish media outlet can adversely affect the health of these populations [29-32].

Out of 136 dietary supplement products with a claim, $80 \%$ did not have rating data available at www.naturaldatabase.com. Furthermore, only one of them had a claim supported by a RCT. These data suggest that there is an urgent need to validate claims of dietary supplement advertisements because many consumers use dietary supplement products for treatment purposes [29].

Our study has some limitations. First, our study is a snapshot of one segment of a calendar year. In addition, although we selected daily and weekly periodicals, TV channels based on reports from reliable media-rating agencies, popularity of media may differ by geographic location. As a result, our results are primarily reflective of the San Francisco and Los Angeles areas. However, the San Francisco and Los Angeles areas may be one of the most suitable places in the US for this type of a study given its diverse population. Second, Spanish language media outlets had a significantly higher rate of dietary supplements that did not contain an identifiable ingredient than the other languages $(p=0.001$ by Fisher's exact test). This limited us to assess validation of a claim in dietary supplement products advertised in Spanish media outlets. Third, we used a strict definition of a therapeutic claim and this resulted in a lower percentage of dietary supplement advertisements with a therapeutic claim than a previous study [5]. Given the somewhat subjective determination of a therapeutic claim in a dietary supplement advertisement recommended by the FTC guidance, our criteria was designed to identify an obvious therapeutic claim [4]. Fourth, we relied on a commercial database and data from RCT for validation of claims made in dietary supplement advertisements. This database is one of the most comprehensive databases on dietary supplements and alternative medicine and its ratings are used on www.medlineplus.gov, a US government website. In addition, data from RCT are considered a gold standard to support the use of medical treatment in clinical practice, although dietary supplements technically do not require this level of evidence for their marketing. Lastly, although median exposure per day across all outlets (not per outlet) or median exposure across outlets adjusted by the relative reach of that outlet (i.e. in terms of persons exposed to the ads) may be more helpful estimates, we were not able to calculate these estimates because data on TV and weekly periodicals were not collected on a daily basis and we do not exactly know the average number of readers/viewers for each outlet, particularly non-English outlets.

\section{Conclusion}

Our data suggest that there is a strong need for enforcement of the regulation on dietary supplement advertisements in non-English media outlets. Because data on claims of many dietary supplement advertisements are not available, rigorous evaluations of their claims should be carried out to guide consumers.

\section{Abbreviations}

CBS: Columbia Broadcasting System; DS: dietary supplements; DSHEA: Dietary Supplement Health and Education Act of 1994; FTC: Federal Trade Commission; KBS: Korean Broadcasting System; RCT: randomized controlled trial.

\section{Competing interest}

Authors have no competing financial interest related to this study.

\section{Authors' contributions}

AL designed the study, collected and analyzed data, and drafted the manuscript. LJV designed the study, collected and analyzed data, and reviewed the manuscript. WCW designed the study, collected and analyzed data, and reviewed the manuscript. JS designed the study, collected and analyzed data, and reviewed the manuscript. All authors read and approved the final manuscript.

\section{Acknowledgements}

We would like to thank the Pathway Project Grant from the UCSF School of Pharmacy for helping to fund this research. The funding source had no role 
in the design of the study; in the collection, analysis, and interpretation of data; in the writing of the manuscript; and in the decision to submit the manuscript for publication.

Received: 19 July 2015 Accepted: 14 December 2015

Published online: 22 December 2015

\section{References}

1. Peregoy JA, Clarke TC, Jones LI, Stussman BJ, Nahin RL. Regional Variation in Use of Complementary Health Approaches by U.S. Adults. Center for Disease Control. http://www.cdc.gov/nchs/data/databriefs/db146.htm. Accessed 9 June 2015

2. Ortiz BI, Shield KM, Clauson KA, Clay PG. Complementary and alternative medicine use among Hispanics in the United States. Ann Pharmacother. 2007:41:994-1004.

3. U.S. Food and Drug Administration. http://www.fda.gov/aboutfda/ transparency/basics/ucm195635.htm. Accessed 1 June 2015.

4. Bureau of Consumer Protection. Federal Trade Commission. Dietary Supplements: An Advertising Guide for Industry. http://www.business.ftc. gov/documents/bus09-dietary-supplements-advertising-guide-industry. Accessed 1 June 2015.

5. Chung EP, Hwang HJ, Kim MK. Evaluation of non-English dietary supplement advertisements in an ethnic minority community in America. Public Health Nutr. 2007:10:834-7.

6. U.S. Census Bureau Census Data. 2010 Census data. http://www.census.gov/ 2010census/data/ Accessed 6/1/2015.

7. ABYZ News Link. San Francisco Newspapers and News Media Guide (2000). http://www.abyznewslinks.com/unitecasf.htm. Accessed 1 June 2013.

8. San Francisco Chronicle. Newspaper war in the Bay Area (2004). http:// www.chineseadvertisingagencies.com/mediaguide/Chinese-newspapersSan-Francisco.html. Accessed 1 June 2013.

9. San Francisco Chronicle. http://www.sfchronicle.com/. Accessed 1 June 2013.

10. Los Angeles Times. http://www.latimes.com/. Accessed 1 June 2013.

11. Mondo Times. Top 100 Newspaper Worldwide (ranked by circulation). http://www.mondotimes.com/newspapers/worldtop100.html. Accessed 1 June 2013.

12. Korea Audit Bureau of Circulations. Korean ABC Organization - Daily Newspapers - 2011 Edition. http://www.kabc.or.kr/.. Accessed 1 June 2013.

13. La Opinion. http://www.laopinion.com/. Accessed 1 June 2013.

14. Hoy. http://www.hoylosangeles.com/. Accessed 1 June 2013.

15. World Journal. http://www.worldjournal.com/. Accessed 1 June 2013.

16. Sing Tao Daily. http://www.singtaousa.com/?variant=zh-hk\&fs=16. Accessed 1 June 2013.

17. SF Weekly. http://www.sfweekly.com/. Accessed 1 June 2013.

18. San Francisco Bay Guardian. http://www.sfbg.com/. Accessed 1 June 2013.

19. El Tecolote. http://eltecolote.org/content/en/. Accessed 1 June 2013.

20. Nielsen. Top 10 List For Prime Broadcast Network TV-United States. http:// www.nielsen.com/us/en/top10s.html . Accessed 1 June 2013.

21. Huffington Post. Univision Sets TV Ratings Milestone. http://www. huffingtonpost.com/2013/07/23/univision-sets-tv-ratings-milestone_n_ 3641381.html. Accessed 1 June 2013.

22. TVB USA. TVB USA E-Newsletter: Exclusive for TVB Advertisers (2012). TVB USA Website. http://www.tvbusa.com/images/content/915/E-Newsletter_ 201212.html Accessed 1 June 2013.

23. AGB Nielsen. Popularity Rating of Major Broadcasters (2013). http://www. agbnielsen.co.kr/index.asp?ref=0. Accessed 1 June 2013.

24. U.S. Department of Health and Human Services. Dietary Supplement Health And Education Act of 1994 (2014). http://www.health.gov/dietsupp/ch1.htm. Accessed 1 June 2015

25. Natural Medicines Comprehensive Database. www.naturaldatabase.com. Accessed 26 October 2014.

26. Shaw $P$, Zhang $V$, Metallinos-Katsaras E. A content analysis of the quantity and accuracy of dietary supplement information found in magazines with high adolescent readership. J Altern Complement Med. 2009;15:159-64.

27. Natural Medicines Comprehensive Database Overview of Editorial Principles and Process. National Library of Medicine - National Institute of Health. http://www.nlm.nih.gov/medlineplus/druginfo/natural/methodology.html. Accessed 26 October 2014

28. Seo HJ, Sung YK, Choi CB, Lee EB, Cheong C, Kim SY, et al. Prevalence and factors affecting glucosamine use in Korea: a survey-based study. Rheumato Int. 2013;33:1627-31.
29. Blendon RJ, Benson JM, Botta MD, et al. Users' Views of Dietary Supplements. JAMA Intern Med. 2013:173:74-6.

30. Avila RM, Bramlett MD. Language and immigrant status effects on disparities in Hispanic children's health status and access to health care. Matern Child Health J. 2013;17:415-23.

31. Heo HH, Sentell TL, Li D, Ahn HJ, Miyamura J, Braun K. Disparities in Potentially Preventable Hospitalizations for Chronic Conditions Among Korean Americans, Hawaii, 2010-2012. Prev Chronic Dis. 2015 doi:10.5888/pcd12.150057.

32. Sentell TL, Tsoh JY, Davis T, Davis J, Braun KL. Low health literacy and cancer screening among Chinese Americans in California: a cross-sectional analysis. BMJ Open. 2015;5:e006104. doi:10.1136/bmjopen-2014-006104.

\section{Submit your next manuscript to BioMed Central and we will help you at every step:}

- We accept pre-submission inquiries

- Our selector tool helps you to find the most relevant journal

- We provide round the clock customer support

- Convenient online submission

- Thorough peer review

- Inclusion in PubMed and all major indexing services

- Maximum visibility for your research

Submit your manuscript at www.biomedcentral.com/submit 